\title{
RESEARCH
}

Open Access

\section{Prevalence of temporomandibular joint disorder in the Lebanese population, and its association with depression, anxiety, and stress}

Elio Kmeid ${ }^{1}$, Mansour Nacouzi ${ }^{1,2}$, Souheil Hallit ${ }^{1,3^{*}+}$ (1) and Ziad Rohayem ${ }^{1,2^{*}+}$

\begin{abstract}
Background: The objectives of this study were to study the prevalence of temporomandibular joint disorder (TMD) and its association with anxiety, depression, and stress among the general Lebanese population as well as in a sample of patients recruited from an otolaryngologist clinic.

Methods: A cross-sectional study was conducted between September 2018 and December 2019, which enrolled 459 participants from all districts of Lebanon (sample 1) and 37 patients from the otolaryngologist clinic at the Eye and Ear Hospital (sample 2). The temporomandibular disorder screening checklist was used to screen for temporomandibular joint disorder. The Fonseca's anamnestic index was used to assess for temporomandibular joint disorder related signs and symptoms, as well as for symptoms severity.

Results: The results showed that $19.7 \%$ of the general Lebanese population had TMD, from which $55.9 \%$ were female. In contrast, 59.5\% of patients in the sample recruited from the clinic were found to have TMD. Higher stress, anxiety, and depression scores were associated with higher temporomandibular disorder severity score $(B=0.23$; $B=0.10$ and $B=0.10$ respectively). Patients in the sample recruited from the clinic had higher mean stress (20.75 vs 11.43 ), anxiety (12.46 vs 5.78), depression (13.24 vs 6.52), and temporomandibular disorder severity scores ( $59.5 \%$ vs 19.7\%) than the general population.
\end{abstract}

Conclusion: Temporomandibular joint disorder appears to be associated significantly with depression, anxiety, and stress and remains largely underdiagnosed in the general population.

Keywords: Temporomandibular joint disorder, Depression, Anxiety, Stress

\footnotetext{
* Correspondence: souheilhallit@hotmail.com; ziadrohayem@gmail.com

${ }^{\dagger}$ Souheil Hallit and Ziad Rohayem are last co-authors.

${ }^{1}$ Faculty of Medicine and Medical Sciences, Holy Spirit University of Kaslik (USEK), Jounieh, Lebanon

Full list of author information is available at the end of the article
}

(c) The Author(s). 2020 Open Access This article is licensed under a Creative Commons Attribution 4.0 International License, which permits use, sharing, adaptation, distribution and reproduction in any medium or format, as long as you give appropriate credit to the original author(s) and the source, provide a link to the Creative Commons licence, and indicate if changes were made. The images or other third party material in this article are included in the article's Creative Commons licence, unless indicated otherwise in a credit line to the material. If material is not included in the article's Creative Commons licence and your intended use is not permitted by statutory regulation or exceeds the permitted use, you will need to obtain permission directly from the copyright holder. To view a copy of this licence, visit http://creativecommons.org/licenses/by/4.0/. The Creative Commons Public Domain Dedication waiver (http://creativecommons.org/publicdomain/zero/1.0/) applies to the data made available in this article, unless otherwise stated in a credit line to the data. 


\section{Background}

Temporomandibular joint disorder is a group of pain conditions that affect the function of the temporomandibular joint, along with the muscles of mastication [1, 2]. Pain in the area around the temporomandibular joint, can be due to diseases from inside the articulation, from adjacent structures, or from a combination of both [3]. There may be associated symptoms, not related to the musculoskeletal system, like tinnitus, referred otalgia, headaches (tension headache or migraine), toothache, neck pain, and myofascial pain [4].

Myofascial TMD pain is the most frequent cause of orofacial pain (42\%), followed by disc displacement with reduction (32.1\%) and arthralgia (30\%) [5]. Myofascial Pain is defined as "pain of muscle origin that is affected by jaw movement, function, or para-function, and replication of this pain occurs with provocation testing of the masticatory muscles spreading beyond the site of palpation but within the boundary of the muscle when using myofascial examination protocol" [6]. In respect to TMD, the term Masticatory Myofascial Pain (MTMD) can be used to describe the myogenic component of the disease.

Temporomandibular joint disorder can affect 5 to $12 \%$ of the population [6]. Some studies have even reported higher incidences up to 25\% [7] and 33\% [8] to 40\% [9] in the general population. Less than $5 \%$ of patients will seek medical treatment [8]. Whereas some patients will more likely seek dental care for their temporomandibular joint symptoms [10]. A systematic review conducted by Lai et $\mathrm{Al}$. has shown the prevalence of TMD among orthodontic patients to range from 21.1 to $73.3 \%$ [11]. According to a World Health Organization (WHO) report, TMD is the third stomatological disorder, after dental caries and periodontal diseases, to be considered a populational disease [12]. The symptoms of temporomandibular joint dysfunction are more common in the female population, compared to males [13-16]. Mcfarlane et Al. (2002) have stated that the prevalence of orofacial pain in temporomandibular joint disorder was 21 and $30 \%$ in males and females, respectively. Young females less than 30 years old are at increased risk of temporomandibular joint disorder [17]. In contrast to the previous reports, some recent studies have shown that temporomandibular joint disorder prevalence reaches its peak between 45 to 64 years of age, before decreasing with older age as older adults seemed to have milder symptoms of temporomandibular joint disorder [18].

The etiologies of temporomandibular joint disorder are biologic, environmental (smoking), emotional (depression and anxiety), social, and cognitive factors. There is a constant association with other pain conditions (like chronic headaches), fibromyalgia, autoimmune disorders (like Sjogren syndrome, rheumatoid arthritis, and lupus erythematosus), psychiatric illness, and sleep apnea [17]. One study has shown an association between temporomandibular joint disorder symptoms and depression, anxiety, oral parafunctions especially bruxism, and hysteria in adolescents [19]. Another one has shown that two important risk factors temporomandibular joint were sleep quality and stress level [20].

Temporomandibular joint disorder has also been shown to be associated with impaired general health status and socioeconomic factors in Sweden (such as higher education level, university degree and chewing with caution) [21]. Another study has shown that increased level of pain has been associated with lower educational level, divorce or separation, and female gender [22]. Racial disparities have also been described as facial and jaw pain were shown to be more frequent among Caucasians, with an earlier onset, compared to African-Americans [23].

People with temporomandibular joint disorder are more commonly affected by anxiety and depression [24]. Civil war in Lebanon has increased the risk of mental health disorders [25]. However, because there is a significant delay in seeking treatment for mental health, mental disorders are underreported [25]. There seems to be a lack of data regarding the prevalence of temporomandibular joint disorder in Lebanon in general and Masticatory Myofascial Pain (MTMD) in particular and its association with levels of anxiety, stress and depression as well as oral parafunctional habits. Therefore, the objectives of this study were to study the prevalence of temporomandibular joint disorder (TMD) and its association with anxiety, depression, and stress among the general Lebanese population as well as in a sample of patients recruited from an otolaryngologist clinic.

\section{Methods \\ Study 1 \\ Study design}

Between September 2018 and December 2019, a proportionate sample from all Lebanese governorates was collected. Each governorate is divided into Caza, which in turn, is divided into a variety of villages (Fig. 1). A simple randomization technique was used to choose two villages and the households from each village. All adults persons in the household were invited to participate. Questionnaires were filled by those who accepted enrollment in the study. Exclusion criteria included patients with congenital craniofacial malformations, reported history of facial trauma, history of TMJ surgery, history of rheumatological or autoimmune disorder, as these are well known causes of TMD $[17,26]$, and a recent $(<6$ weeks) dentists visit, raising suspicion of dental disease which can mimic symptoms of TMD [17, 26]. In 


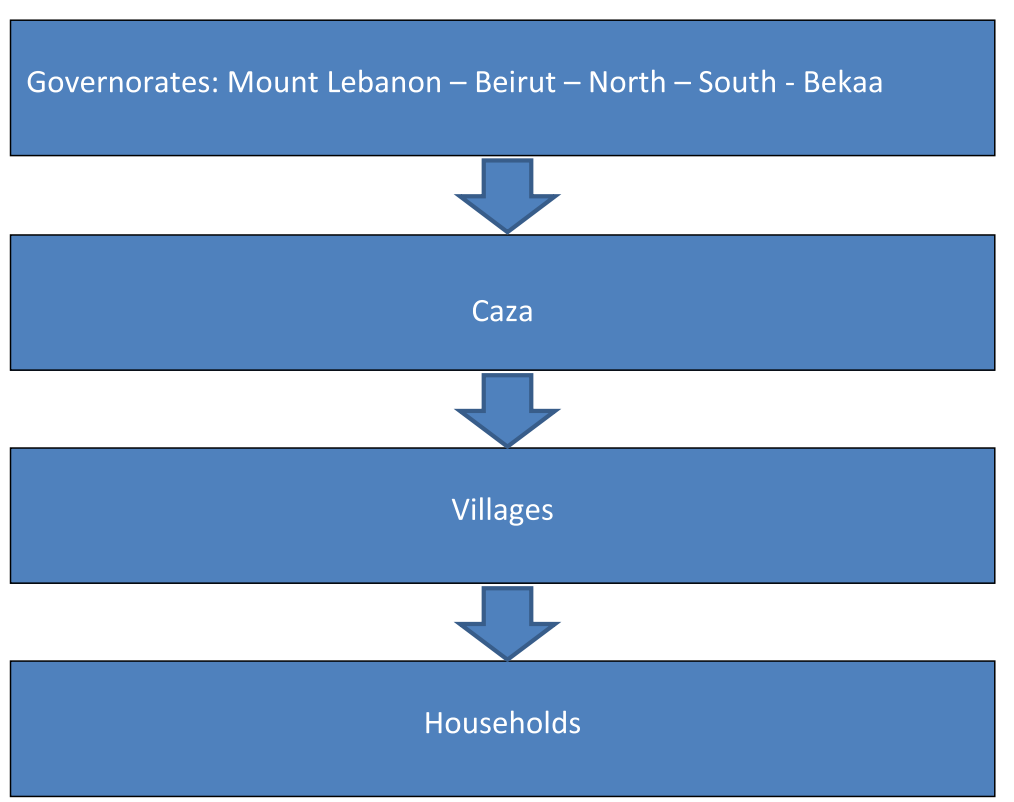

Fig. 1 Diagrammatic representation for participant selection

addition, people already taking medications for depression, anxiety, and stress, were also excluded, as the score severity of each of depression, anxiety, and stress might be affected and lowered by these.

\section{Minimal sample size calculation}

Based on the formula $n=\frac{\left(Z_{1-\alpha / 2}\right)^{2} p(1-p)}{d^{2}}$, where $n=$ size of the sample, $p=$ expected proportion and $\mathrm{d}=$ the desired margin of error and $Z_{1-\alpha / 2}=1.96$ for $\alpha=5 \%$, a minimal sample of 384 participants was needed, based on a $p=50 \%$ expected frequency of TMJ in the absence of similar studies in the country and a $d=5 \%$ risk of error; 510 questionnaires were distributed, and 443 $(86.86 \%)$ were collected back.

\section{Translation}

A translation procedure from English to Arabic of all non-validated scales was made by one specialized translator, then back to English by a different translator. Then, a comparison of the two English versions was made to make sure that no contradictions exist between the 2 versions. Discrepancies were resolved by consensus. A pilot study on 20 participants was first conducted; no significant changes were made to the questionnaire content, therefore, these patients were included in the final database.

\section{Questionnaire}

The questionnaire used was in two languages, the English language and the translated version to the native language of Lebanon (Arabic), and left for the participant preference. The first part of the questionnaire assessed the sociodemographic characteristics of the included participants (age, gender, education level, socioeconomic level, sociodemographic level, weight, height), and the other part consisted of the different scales used in this study:

\section{Temporomandibular disorder screening checklist}

This short and high validity screening checklist goal, is for primary TMD screening in general practice [27]. TMD screening is of practical importance in dentistry. Plus, it could be of use in general population settings to determine one's capabilities to execute some tasks, like in military, where personnel are to be deployed and moved to areas where a treatment for acute pain episodes will be difficult [28].

\section{Fonseca's anamnestic index}

It consisted of measuring the TMD severity using the FAI questionnaire. It is composed of 10 questions with three answer options, each one of them assigned to a score: yes $=10$ points, sometimes $=5$ points and no $=0$. According to the total results obtained to each individual, subjects were categorized to no TMD (0-3), mild TMD (5-9), moderate TMD (10-14), or severe TMD $(15-19)[29,30]$.

\section{PHQ-9 questionnaire}

It consisted of nine items assessing depression and its severity: mild, moderate, moderately severe, and severe depression, represented by cutoffs values of 5, 10, 15, and 20 , respectively [31]. 


\section{GAD-7}

It aimed at screening for general anxiety disorder. It has been demonstrated as an effective and valid tool for measuring its severity practically and in the research setting. Higher scores reflect higher anxiety [32]. Both PHQ-9 and GAD-7 scales have been previously validated in Lebanon [33].

\section{Beirut Distress Scale (BDS22)}

Developed and validated in Lebanon, this scale assesses mental distress, with higher scores indicative of higher psychological distress) [34].

\section{Study 2}

In addition, a random sample of adult patients coming to an otolaryngologist clinic with head and neck symptoms were selected. Adults (18 years old and more) were eligible to participate. The exact same exclusion criteria were applied to sample 2 . More specifically, patients previously diagnosed or treated for TMD were excluded. The purpose of sample two was to present a "real-life scenario" alternative to sample 1 . The hypothesis was to see whether patients presenting to ENT clinic suffering from any ENT-related complaint had a higher incidence of TMD than the general population. This was based on the impression that patient with TMD tend to visit otolaryngologists more frequently than dentists, neurologists or rheumatologists because they tend to present frequently with referred otalgia. This raises the point of lack of awareness among patients and physicians alike on the common presentation and screening of TMD. As for sample 1, screening of TMD was solely based on anamnesis and findings on physical exam were not included in the analysis. This was done purposely to apply same diagnostic criteria among the two sample as the main purpose of sample 2 as previously noted was to compare incidence of undiagnosed-untreated TMD among the 2 samples.

\section{Statistical analysis}

Statistical Package for Social Science (SPSS) version 23 was used for the statistical analyses. Weighting to the general population was performed in terms of age, gender, and mouhafaza. Descriptive statistics were presented using mean and standard deviation for continuous measures, frequencies and percentages for categorical variables. The Student $\mathrm{t}$-test and ANOVA test were used to assess the association between each continuous independent variable (PHQ-9, GAD-7 and BDS22 scores) and the sociodemographic and other variables. To calculate the $p$-value of the statistical significance, the Bonferroni correction compensates for that increase by testing each individual hypothesis at a significance level of $\alpha / \mathrm{m}$, where $\alpha$ is the desired overall alpha level and $m$ is the number of hypotheses/tests conducted (24). Concerning the knowledge, attitude and practice scores, we tested 27 hypotheses/variables in each model, with a desired error $\alpha$ of 0.05 ; therefore, the Bonferroni correction would test each individual hypothesis at a $p$-value of $0.05 / 27=$ 0.002 . Multivariable linear regression models were done to explore factors associated with the three scores as dependent variables and taking all variables that showed a $p \leq 0.002$ in the bivariate analysis as independent variables. A $p<0.05$ in the multivariable model was considered significant. Scales' reliability was assessed using Cronbach's alpha.

\section{Results}

High Cronbach's alpha values were obtained for all the scales as follows: FAI (0.783), PHQ-9 (0.831), GAD-7 (0.868) and BDS22 (0.923).

\section{Study 1}

\section{Sociodemographic and other characteristics}

The results of the sociodemographic characteristics are summarized in Table 1 . The mean age of the participants was $30.88 \pm 14.50$ years. $54.7 \%$ were of female gender. $87(19.7 \%)$ of the participants had TMJ [95\% CI $0.160-0.234]$, with a mean TMD severity (FAI score) of $22.02 \pm 17.50 .55 .9 \%$ of patients with TMD were female.

Table 1 Sociodemographic characteristics of the participants $(N=443)$

\begin{tabular}{ll}
\hline Variable & N (\%) \\
\hline Gender & $196(45.3 \%)$ \\
Male & $237(54.7 \%)$ \\
Female & \\
Mouhafaza & $43(10.6 \%)$ \\
Beirut & $156(38.6 \%)$ \\
Mount Lebanon & $77(19.1 \%)$ \\
North & $52(12.9 \%)$ \\
South & $76(18.8 \%)$ \\
Bekaa & \\
Education level & $18(4.2 \%)$ \\
Illiterate/primary/complementary & $168(38.8 \%)$ \\
Secondary & $247(57.0 \%)$ \\
University & \\
Monthly income & $106(34.3 \%)$ \\
$<1000$ USD & $135(43.7 \%)$ \\
1000-2000 USD & $68(22.0 \%)$ \\
$>$ 2000 USD & \\
Mean \pm SD & $30.88 \pm 14.50$ \\
Age (in years) & $24.27 \pm 6.94$ \\
\hline Body Mass Index (Kg/m²)
\end{tabular}


Table 2 Bivariate analysis of factors associated with depression, anxiety and stress

\begin{tabular}{|c|c|c|c|}
\hline Variable & Depression & Anxiety & Stress \\
\hline \multicolumn{4}{|l|}{ Gender } \\
\hline Male & $5.92 \pm 4.17$ & $5.10 \pm 3.49$ & $10.24 \pm 8.44$ \\
\hline Female & $6.97 \pm 4.75$ & $6.32 \pm 4.34$ & $12.41 \pm 10.11$ \\
\hline$p$ & 0.035 & 0.007 & 0.042 \\
\hline \multicolumn{4}{|l|}{ Governorate } \\
\hline Beirut & $6.23 \pm 4.43$ & $6.67 \pm 3.29$ & $9.53 \pm 9.54$ \\
\hline Mount Lebanon & $6.81 \pm 4.60$ & $6.06 \pm 4.28$ & $12.42 \pm 9.76$ \\
\hline North & $6.26 \pm 5.12$ & $5.40 \pm 4.07$ & $11.14 \pm 9.68$ \\
\hline South & $6.67 \pm 4.91$ & $6.11 \pm 4.39$ & $11.52 \pm 8.70$ \\
\hline Bekaa & $6.03 \pm 3.69$ & $4.87 \pm 3.36$ & $10.49 \pm 8.88$ \\
\hline$p$ & 0.729 & 0.065 & 0.243 \\
\hline \multicolumn{4}{|l|}{ Education level } \\
\hline Illiterate/primary/ complementary & $4.22 \pm 3.93$ & $4.39 \pm 3.96$ & $8.17 \pm 8.31$ \\
\hline Secondary & $6.80 \pm 4.81$ & $5.91 \pm 4.24$ & $12.97 \pm 10.26$ \\
\hline University & $6.47 \pm 4.32$ & $5.73 \pm 3.91$ & $10.44 \pm 8.72$ \\
\hline$p$ & 0.074 & 0.330 & 0.018 \\
\hline \multicolumn{4}{|l|}{ Monthly income } \\
\hline$<1000$ USD & $6.47 \pm 4.42$ & $5.23 \pm 3.48$ & $11.16 \pm 8.68$ \\
\hline 1000-2000 USD & $6.38 \pm 4.36$ & $5.81 \pm 4.10$ & $10.52 \pm 9.19$ \\
\hline$>2000$ USD & $5.83 \pm 4.26$ & $5.13 \pm 3.30$ & $10.19 \pm 8.21$ \\
\hline$p$ & 0.617 & 0.510 & 0.684 \\
\hline \multicolumn{4}{|l|}{ Sleep apnea } \\
\hline No & $6.35 \pm 4.27$ & $5.59 \pm 3.75$ & $10.98 \pm 8.90$ \\
\hline Yes & $7.97 \pm 5.40$ & $7.36 \pm 5.07$ & $14.65 \pm 11.57$ \\
\hline$p$ & 0.036 & 0.014 & 0.027 \\
\hline \multicolumn{4}{|l|}{ Cigarette smoking } \\
\hline No & $6.43 \pm 4.44$ & $5.73 \pm 4.02$ & $11.12 \pm 9.01$ \\
\hline Yes & $7.09 \pm 4.88$ & $6.09 \pm 4.18$ & $13.43 \pm 11.23$ \\
\hline$p$ & 0.364 & 0.667 & 0.264 \\
\hline \multicolumn{4}{|l|}{ Waterpipe smoking } \\
\hline No & $6.49 \pm 4.56$ & $5.79 \pm 4.04$ & $11.22 \pm 9.22$ \\
\hline Yes & $6.73 \pm 4.25$ & $5.76 \pm 4.04$ & $12.82 \pm 10.29$ \\
\hline$p$ & 0.503 & 0.931 & 0.278 \\
\hline \multicolumn{4}{|l|}{ Bruxism at night } \\
\hline No & $6.12 \pm 4.34$ & $5.53 \pm 3.85$ & $10.71 \pm 8.81$ \\
\hline Yes & $7.91 \pm 4.43$ & $6.62 \pm 4.08$ & $14.09 \pm 10.53$ \\
\hline$p$ & 0.001 & 0.051 & 0.008 \\
\hline \multicolumn{4}{|l|}{ Dental gutter } \\
\hline No & $6.36 \pm 4.53$ & $5.75 \pm 4.06$ & $11.02 \pm 9.31$ \\
\hline Yes & $7.75 \pm 4.33$ & $6.17 \pm 3.84$ & $14.18 \pm 9.60$ \\
\hline$p$ & 0.012 & 0.275 & 0.017 \\
\hline \multicolumn{4}{|l|}{ Presence of TMJ } \\
\hline No & $6.21 \pm 4.41$ & $5.50 \pm 3.95$ & $10.82 \pm 9.04$ \\
\hline Yes & $7.77 \pm 4.69$ & $6.91 \pm 4.19$ & $13.88 \pm 10.47$ \\
\hline
\end{tabular}


Table 2 Bivariate analysis of factors associated with depression, anxiety and stress (Continued)

\begin{tabular}{llll}
\hline Variable & Depression & Anxiety & Stress \\
\hline$p$ & 0.005 & 0.01 & 0.015 \\
Kind of work & & & $13.04 \pm 10.60$ \\
Desk & $7.43 \pm 5.03$ & $6.55 \pm 4.42$ & $11.05 \pm 8.66$ \\
Standing & $6.00 \pm 4.24$ & $5.61 \pm 4.10$ & $9.33 \pm 8.87$ \\
Computer & $5.97 \pm 4.35$ & $5.23 \pm 3.39$ & 0.036 \\
$p$ & 0.042 & 0.08 & \\
\hline
\end{tabular}

Numbers in bold indicate significant $p$-values based on the corrected $p \leq 0.002$

The mean depression score was $6.51 \pm 4.51$, anxiety $5.78 \pm 4.04$ and the mean stress score was $11.43 \pm 9.40$.

Pain in the jaw was the most reported symptoms (69.1\%) followed by pain in the ear $(50.5 \%)$, pain in front of the ear $(43.6 \%)$, pain in the temple $(42.1 \%)$ and finally facial pain (36\% of the patients).

\section{Bivariate analysis}

Tables 2 and 3 summarize the results of the bivariate analysis of variables associated with depression, anxiety and stress. A higher depression score was found to be significantly associated with bruxism at night compared to not. A higher number of working hours per day was significantly associated with higher depression, whereas a higher number of hours on the phone per day was correlated with higher TMD severity and higher depression, anxiety and stress. Higher age was significantly associated with lower depression and stress.

\section{Multivariable analysis (presence vs absence of TMJ pain)}

The results of a first linear regression, taking depression (PHQ-9 score) as the dependent variable, showed that having bruxism at night $(B=2.29)$ and a higher number of working hours per day $(\mathrm{B}=0.21)$ were significantly associated with higher depression, whereas higher age $(B=-0.09)$ was significantly associated with lower depression (Table 4, Model 1).

Table 3 Bivariate analysis of continuous variables associated with depression, anxiety and stress

\begin{tabular}{llll}
\hline Variable & Depression & Anxiety & Stress \\
\hline Age & $-\mathbf{0 . 1 9 8}$ & -0.125 & $\mathbf{- 0 . 1 8 4}$ \\
Body Mass Index & -0.044 & -0.114 & -0.035 \\
Working hours daily & $\mathbf{0 . 1 7 8}$ & 0.153 & 0.047 \\
Hours on phone daily & $\mathbf{0 . 1 9 9}$ & $\mathbf{0 . 1 5 4}$ & $\mathbf{0 . 2 1 5}$ \\
Disorder severity (FAl score) & $\mathbf{0 . 4 7 2}$ & $\mathbf{0 . 4 0 7}$ & $\mathbf{0 . 4 6 6}$ \\
Cumulative cigarette smoking & 0.041 & 0.047 & 0.074 \\
Cumulative waterpipe smoking & 0.033 & 0.002 & 0.075 \\
\hline
\end{tabular}

Numbers in bold indicate significant $p$-values based on the corrected $\mathrm{p} \leq 0.002$.
The results of a second linear regression, taking anxiety (GAD-7 scores) as the dependent variable, showed that the presence of TMD $(B=1.39)$ and a higher number of hours on the phone per day $(B=0.18)$ were significantly associated with higher anxiety (Table 4, Model 2).

The results of a third linear regression, taking stress (BDS22 scores) as the dependent variable, showed that the presence of TMD $(B=3.48)$ and a higher number of hours on the phone per day $(B=0.43)$ were significantly associated with higher stress, whereas higher age $(B=-$ 0.12) was significantly associated with lower stress (Table 4, Model 3).

\section{Multivariable analysis (pain severity)}

The results of a first linear regression, taking depression (PHQ-9 score) as the dependent variable, showed that a higher TMD score $(B=0.10)$, having bruxism at night $(B=1.12)$ and a higher number of working hours per day $(B=0.17)$ were significantly associated with higher depression, whereas higher age $(B=-0.06)$ was significantly associated with lower depression (Table 5, Model 1).

The results of a second linear regression, taking anxiety (GAD-7 scores) as the dependent variable, showed that a higher TMD severity score $(B=0.10)$ and a higher number of hours on the phone per day $(B=0.13)$ were significantly associated with higher anxiety (Table 5, Model 2).

The results of a third linear regression, taking stress (BDS22 scores) as the dependent variable, showed that a higher TMD severity score $(B=0.23)$ and a higher number of hours on the phone per day $(B=0.37)$ were significantly associated with higher stress, whereas higher age $(B=-0.07)$ was significantly associated with lower stress (Table 5, Model 3).

\section{Study 2}

Comparison between the sample from the general population and that recruited from the ENT clinic

Higher mean depression, anxiety, stress and TMD severity scores were significantly found in the sample recruited from the clinic compared to that from the general population (Table 6). Moreover, a significantly higher percentage of patients who came to the clinic had 
Table 4 Multivariable analysis taking the depression, anxiety and stress scores as dependent variables and the presence/absence of TMD as an independent variable

\begin{tabular}{|c|c|c|c|c|c|}
\hline \multicolumn{6}{|c|}{ Model 1: Linear regression taking depression (PHQ-9 score) as the dependent variable. } \\
\hline Variable & UB & SB & $p$ & \multicolumn{2}{|c|}{ 95\% Confidence Interval } \\
\hline Age & -0.09 & -0.26 & $<0.001$ & -0.12 & -0.05 \\
\hline Bruxism at night (yes vs no*) & 2.29 & 0.20 & $<0.001$ & 1.13 & 3.44 \\
\hline Working hours per day & 0.21 & 0.13 & 0.009 & 0.05 & 0.37 \\
\hline Presence vs absence ${ }^{*}$ of TMD & 0.92 & 0.08 & 0.137 & -0.29 & 2.12 \\
\hline \multicolumn{6}{|c|}{ Model 2: Linear regression taking anxiety (GAD-7 score) as the dependent variable. } \\
\hline Variable & UB & SB & $p$ & \multicolumn{2}{|c|}{ 95\% Confidence Interval } \\
\hline Hours on phone per day & 0.18 & 0.18 & $<0.001$ & 0.08 & 0.28 \\
\hline Presence vs absence ${ }^{*}$ of TMD & 1.39 & 0.14 & 0.006 & 0.40 & 2.39 \\
\hline \multicolumn{6}{|c|}{ Model 3: Linear regression taking stress (BDS22 score) as the dependent variable. } \\
\hline Variable & UB & SB & $p$ & \multicolumn{2}{|c|}{ 95\% Confidence Interval } \\
\hline Hours on phone per day & 0.43 & 0.18 & $<0.001$ & 0.20 & 0.67 \\
\hline Age & -0.12 & -0.17 & 0.001 & -0.18 & -0.05 \\
\hline Presence vs absence ${ }^{*}$ of TMD & 3.48 & 0.15 & 0.003 & 1.22 & 5.74 \\
\hline
\end{tabular}

*Reference group; UB Unstandardized Beta, SB Standardized Beta

TMD compared to the general population $(59.5 \%$ vs $19.7 \% ; p<0.001)$. These results indicate that $19.7 \%$ of TMD remain undiagnosed in the general population.

\section{Discussion}

To the best of our knowledge, this is the first study to be conducted in Lebanon to target the prevalenc of temporomandibular joint disorder, and its association with anxiety, depression, and stress. Furthermore, no previously published studies have ever compared the severity of TMD, stress, anxiety, and depression between a sample recruited from the clinic, and another one from the general population.

\section{Analysis of the results}

First, our study has shown that the prevalence of undiagnosed temporomandibular joint disorder among the Lebanese population is $19.7 \%$. Moreover, people having a higher TMD severity score were more likely to have bruxism at night, and a higher number of working hours

Table 5 Multivariable analysis taking the depression, anxiety and stress scores as dependent variables and the TMDseverity score as an independent variable

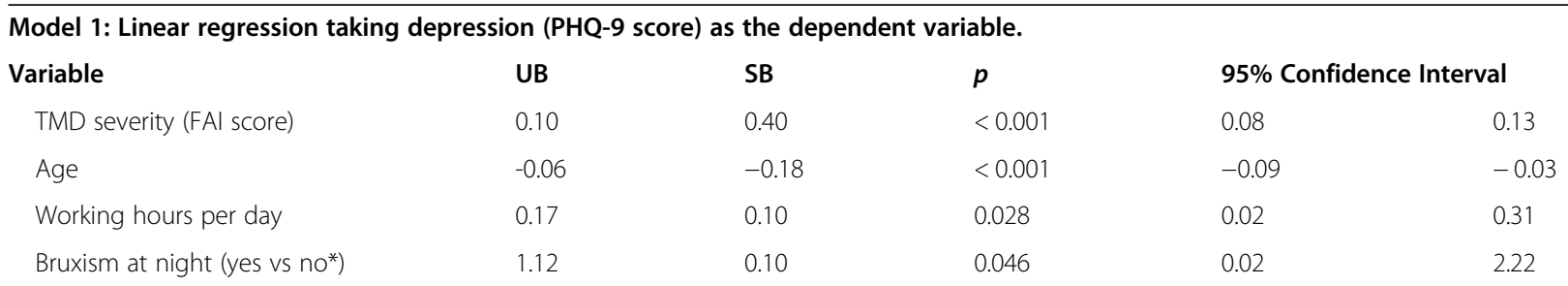

Model 2: Linear regression taking anxiety (GAD-7 score) as the dependent variable.

\section{Variable}

TMD severity (FAl score)

Hours on phone per day

\section{UB}

0.10

0.13
SB

0.45

0.13 $p$

$<0.001$

0.005
95\% Confidence Interval

0.08

0.04

95\% Confidence Interval

$0.18 \quad 0.28$

$0.15 \quad 0.58$

$-0.13$
0.12

0.22

Model 3: Linear regression taking stress (BDS22 score) as the dependent variable.

$\begin{array}{llll}\text { Variable } & \text { UB } & \text { SB } & \boldsymbol{p} \\ \text { TMD severity (FAl score) } & 0.23 & 0.42 & <0.001 \\ \text { Hours on phone per day } & 0.37 & 0.15 & <0.001 \\ \text { Age } & -0.07 & -0.10 & 0.031\end{array}$

*Reference group; UB Unstandardized Beta, SB Standardized Beta

Variables entered in the models: Model 1: Bruxism at night, age, FAI pain severity score, hours on the phone per day; Model 2: FAI pain severity score, hours on the phone per day; Model 3: FAl pain severity score, hours on the phone per day, age. 
Table 6 Comparison between the sample from the general population and the clinic one

\begin{tabular}{llll}
\hline Variable & General population & Clinic & $\boldsymbol{p}$ \\
\hline Depression & $6.52 \pm 4.51$ & $13.24 \pm 7.35$ & $<0.001$ \\
Anxiety & $5.78 \pm 4.03$ & $12.46 \pm 5.65$ & $<0.001$ \\
Stress & $11.43 \pm 9.40$ & $20.75 \pm 18.94$ & 0.029 \\
TMD severity (FAl score) & $22.02 \pm 17.50$ & $59.86 \pm 18.80$ & $<0.001$ \\
\hline
\end{tabular}

per day. They were also more likely to have higher depression scores, whereas older age was associated with lower depression and stress levels. The presence of TMD and having a higher TMD severity score was also associated with higher number of hours spent on the phone per day and higher anxiety and stress levels. In addition, a higher mean depression, anxiety, stress, and TMD severity scores were found in the clinic sample, compared to the general population sample. This correlated with the fact that a higher percentage of patients recruited from the clinic had a TMD, compared to the general population. Otolaryngologists are among the first-line physicians dealing with TMD. This could be explained by the relative high incidence of referred otalgia in the TMD group pushing patients to consult ENT to rule-out otitis.

\section{Study results compared to international studies}

Our study has shown that the prevalence of TMD among the Lebanese participants was $19.7 \%$. It was significantly higher than its prevalence in the US (4.6\%) [35]. A study conducted on physicians in Saudi Arabia showed also a high prevalence of TMJ disorders (37\%) [1]. TMD symptoms were also found to affect $39.2 \%$ of Brazilian population in a study conducted by Goncalves et al. [36]. When focusing on university students, the prevalence of TMD was $46.1 \%$ in Mexico [37], $42.9 \%$ in Taiwan [38], 49.7\% in North Saudi University [39], and $53.21 \%$ [30] to $68 \%$ [40] in Brazil.

Signs and symptoms of TMD were more common in the female population, which comes in agreement with other studies [16, 41]. In our current study, we have found that the most common symptom of TMD was pain in the jaw (69.1\%), as reported in other studies [41, 42]. In our study, $19.7 \%$ of patients with TMD remained undiagnosed, yet they presented sometimes the typical signs and symptoms of TMD, and sometimes even with a high severity scores. We have found a strong association between TMD and depression, as shown in other studies [43]. Anxiety was also associated with TMD in our study, which is in agreement with findings in another study made among university undergraduate students [44] and among pre-university students in relation to stress attributed to their university entrance exam [45].
There was a significant association between stress level and presence of TMD. This finding has mirrored that of multiple other studies [45-48].

Our study has shown that the higher number of hours spent on the phone per day, was associated with higher depression, anxiety and stress scores and higher TMD severity score. In fact, studies have shown that cell phone use is one of the variables associated with the general health of medical students, affecting it negatively [49-51]. Moreover, ergonomic factors related to workplace environment are risk factors for developing neck pain [52]. Effective ergonomic interventions can reduce neck-shoulder pain [53] and predefined activities can help limiting the overuse of cellphones, thus improving sleep quality [51] and potentially reducing anxietyrelated behavior and bruxism.

\section{Results explanation}

The probable association between stress, anxiety and temporomandibular joint disorder is that psychological factors are able to produce oral parafunctional habits [45], and that they are associated with a lower pressure pain threshold, affecting masticatory muscle tenderness [54]. The Lebanese population, specifically within the 30-40 years old age group can be considered a war generation having witnessed 15 years of civil war and unrest and thus maybe more prone to anxiety, stress, depression or even mental disorders [55]. Some of these disorders remains underdiagnosed as a social stigma exists towards mental disorders [56], and those seeking treatment for it [57].

\section{Practical implications and directions for future research} Earlier screening of TMD and thus early intervention with cognitive behavioral therapy leads to better results [58]. Physicians should counsel and educate patients on good oral habits, lifestyle modifications (less hours on a screen, phone ...) and if needed refer to dentists as well as screen and treat underlining associated anxiety and depression. TMD may need the collaboration between multiple health specialists, including otolaryngologists, dentists, physiotherapists, and oral and maxillofacial surgeons [59]. High quality studies are needed to better define the use of medications, and better understand the risks and benefits of any drug used [60]. In addition, new diagnostic imaging techniques must be explored to further evaluate the relationship between tinnitus and TMD [61].

\section{Limitations}

An attrition bias is possible because of the refusal rate. A selection bias is also possible since the sample is not representative of the whole population. Information bias might also be present since some questions might be 
over- or underestimated by the participants. In addition, to better evaluate the association between stress, anxiety and temporomandibular joint disorder, the latter should be classified into its different subtypes [9]. Temporomandibular Disorders (TMDs) is a general term that includes a group of clinical conditions affecting the temporomandibular joint, the masticatory musculature and associated head and neck musculoskeletal structures. Masticatory Myofascial Pain refers to the myogenic component of the disease which is considered to be the most prevalent. The present study did not segregate between the two major subgroups of TMD: a myogenic facial pain (MFP) group and a TMJ internal derangement (TMJID) group. The primary differentiation between the 2 subgroups is based on meniscus displacement present with TMJID patients and this was not identified in our study which relied primary on anamnesis rather than on physical examination. While most of the patients sampled in our study likely belong to the MFP group, a TMJID component cannot be ruled out based on history alone. It is in the light of this distinction that our results must be interpreted. Previous authors [24] have shown that anxiety scores in TMD with muscle disorder and TMD with joint disorder were the same, whereas the prevalence of depression was higher in TMD with muscle disorder than TMD with joint disorder. This resonates with our study results showing a high prevalence of depression likely indicating a comorbidity of the MFP subtype of TMD represented in our population. Another limitation resides in the fact that the scales (except PHQ-9, GAD-7 and BDS-22) have not been validated in Lebanon. Last and not least, since our study is a cross-sectional one, the association and correlation between the variables does not always mean causation.

\section{Conclusion}

This study has shown that TMD remains largely underdiagnosed in the Lebanese population and that it correlates well with anxiety, stress, depression and bad oral and lifestyle habits. We need to raise awareness among the population and health professional alike to better screen for and treat TMD.

\section{Abbreviations \\ TMD: Temporomandibular joint disorder; TMJ: Temporomandibular joint; WHO: World Health Organization; GAD: Generalized anxiety disorder; BDS22: Beirut Distress Scale; SPSS: Statistical Package for Social Science}

\section{Acknowledgments}

We express our gratitude to the participants who donated their time in completing the questionnaires.

\section{Authors' contributions}

EK and MN were responsible for the data collection; EK drafted the manuscript; SH carried out the analysis and interpreted the results, assisted in drafting and reviewing the manuscript; ZR designed the study and was the project supervisor. All authors reviewed the final manuscript and gave their consent. The author(s) read and approved the final manuscript.

Funding

None.

\section{Availability of data and materials}

All data generated or analyzed during this study are not publicly available to maintain the privacy of the individuals' identities. The dataset supporting the conclusions is available upon request to the corresponding author.

\section{Ethics approval and consent to participate}

The Eye and Ear hospital ethics committee approved this study protocol (reference number not available as per the ethics committee). A written informed consent was obtained from each participant.

\section{Consent for publication}

Not applicable.

\section{Competing interests}

The authors have nothing to disclose.

\section{Author details}

${ }^{1}$ Faculty of Medicine and Medical Sciences, Holy Spirit University of Kaslik (USEK), Jounieh, Lebanon. ${ }^{2}$ Department of otorhinolaryngology, Eye and Ear Hospital, Naccache, Lebanon. ${ }^{3}$ INSPECT-LB: Institut National de Santé

Publique, Épidémiologie Clinique et Toxicologie- Liban, Beirut, Lebanon.

Received: 25 March 2020 Accepted: 1 September 2020

Published online: 04 September 2020

\section{References}

1. Al Hayek SO, Al-Thunayan MF, AlGhaihab AM, AlReshaid RM, Omair A. Assessing stress associated with temporomandibular joint disorder through Fonseca's anamnestic index among the Saudi physicians. Clin Exp Dent Res. 2019;5(1):52-8.

2. Rajan $R$, Sun $Y M$. Reevaluating antidepressant selection in patients with bruxism and Temporomandibular joint disorder. J Psychiatr Pract. 2017;23(3): 173-9.

3. Meyer RA. Temporomandibular joint pain. In: Walker HK, Hall WD, Hurst JW, editors. Clinical Methods: The History, Physical, and Laboratory Examinations. Boston: Butterworths Butterworth Publishers, a division of Reed Publishing; 1990

4. Magnusson T, Egermarki I, Carlsson GE. A prospective investigation over two decades on signs and symptoms of temporomandibular disorders and associated variables. A final summary. Acta Odontol Scand. 2005;63(2):99109.

5. Fernandez-de-las-Penas C, Svensson P. Myofascial Temporomandibular disorder. Curr Rheumatol Rev. 2016;12(1):40-54.

6. Schiffman E, Ohrbach R, Truelove E, et al. Diagnostic criteria for Temporomandibular disorders (DC/TMD) for clinical and research applications: recommendations of the international RDC/TMD consortium network* and Orofacial pain special interest Groupdagger. J Oral Facial Pain Headache. 2014;28(1):6-27.

7. Murphy MK, MacBarb RF, Wong ME, Athanasiou KA. Temporomandibular disorders: a review of etiology, clinical management, and tissue engineering strategies. Int J Oral Maxillofac Implants. 2013;28(6):e393-414.

8. Aceves-Avila FJ, Chavez-Lopez M, Chavira-Gonzalez JR, Ramos-Remus C. Temporomandibular joint dysfunction in various rheumatic diseases. Reumatismo. 2013;65(3):126-30.

9. Calixtre LB, Grüninger BLS, Chaves TC, Oliveira AB. Is there an association between anxiety/depression and temporomandibular disorders in college students? J Applied Oral Sci. 2014;22(1):15-21.

10. Schiffman E, Ohrbach R, Truelove E, et al. Diagnostic criteria for Temporomandibular disorders (DC/TMD) for clinical and research applications: recommendations of the international RDC/TMD consortium network* and Orofacial pain special interest groupt. J Oral Facial Pain Headache. 2014;28(1):6-27.

11. Lai YC, Yap AU, Turp JC. Prevalence of temporomandibular disorders in patients seeking orthodontic treatment: a systematic review. J Oral Rehabil. 2020:47(2):270-80 
12. Pihut M, Szuta M, Ferendiuk E, Zeńczak-Więckiewicz D. Differential diagnostics of pain in the course of trigeminal neuralgia and temporomandibular joint dysfunction. Biomed Res Int. 2014;2014:563786

13. Bagis B, Ayaz EA, Turgut S, Durkan R, Ozcan M. Gender difference in prevalence of signs and symptoms of temporomandibular joint disorders: a retrospective study on 243 consecutive patients. Int J Med Sci. 2012;9(7): 539-44

14. Johansson A, Unell L, Carlsson GE, Soderfeldt B, Halling A. Gender difference in symptoms related to temporomandibular disorders in a population of 50-year-old subjects. J Orofac Pain. 2003;17(1):29-35.

15. Macfarlane TV, Blinkhorn AS, Davies RM, Kincey J, Worthington HV. Orofacial pain in the community: prevalence and associated impact. Community Dent Oral Epidemiol. 2002;30(1):52-60.

16. Feteih RM. Signs and symptoms of temporomandibular disorders and oral parafunctions in urban Saudi Arabian adolescents: a research report. Head Face Med. 2006;2:25

17. Gauer RL, Semidey MJ. Diagnosis and treatment of temporomandibular disorders. Am Fam Physician. 2015;91(6):378-86.

18. Yadav S, Yang Y, Dutra EH, Robinson JL, Wadhwa S. Temporomandibular joint disorders in older adults. J Am Geriatr Soc. 2018;66(6):1213-7.

19. Atsu SS, Guner S, Palulu N, Bulut AC, Kurkcuoglu I. Oral parafunctions, personality traits, anxiety and their association with signs and symptoms of temporomandibular disorders in the adolescents. Afr Health Sci. 2019;19(1): 1801-10.

20. Ozdinc SP, Ata HM, Selcuk HM, Can HBM, Sermenli NM, Turan FNP. Temporomandibular joint disorder determined by Fonseca anamnestic index and associated factors in 18- to 27-year-old university students. Cranio. 2020;38(5):327-332. https://doi.org/10.1080/08869634.2018.1513442.

21. Yekkalam N, Wanman A. Associations between craniomandibular disorders, sociodemographic factors and self-perceived general and oral health in an adult population. Acta Odontol Scand. 2014;72(8):1054-65.

22. Blanco-Hungria A, Rodriguez-Torronteras A, Blanco-Aguilera A, et al. Influence of sociodemographic factors upon pain intensity in patients with temporomandibular joint disorders seen in the primary care setting. Medicina oral, patologia oral y cirugia bucal. 2012;17(6):e1034-41.

23. Plesh O, Crawford PB, Gansky SA. Chronic pain in a biracial population of young women. Pain. 2002;99(3):515-23.

24. Calixtre LB, Gruninger BL, Chaves TC, Oliveira AB. Is there an association between anxiety/depression and temporomandibular disorders in college students? J Appl Oral Sci. 2014;22(1):15-21.

25. Karam EG, Mneimneh ZN, Dimassi H, et al. Lifetime prevalence of mental disorders in Lebanon: first onset, treatment, and exposure to war. PLoS Med. 2008;5(4):e61.

26. Scrivani SJ, Keith DA, Kaban LB. Temporomandibular disorders. N Engl J Med. 2008:359(25):2693-705.

27. Zhao NN, Evans RW, Byth K, Murray GM, Peck CC. Development and validation of a screening checklist for temporomandibular disorders. J Orofac Pain. 2011;25(3):210-22.

28. Gonzalez YM, Schiffman E, Gordon SM, et al. Development of a brief and effective temporomandibular disorder pain screening questionnaire: reliability and validity. J Am Dental Assoc (1939). 2011;142(10):1183-91.

29. Fonseca DM, Bonfante G, Valle AL, Freitas SFT. Diagnóstico pela anamnese da disfunção craniomandibular. Revista gaúcha de Odontologia. 1994;42(1): 23-8.

30. Nomura K, Vitti M, Oliveira AS, et al. Use of the Fonseca's questionnaire to assess the prevalence and severity of temporomandibular disorders in Brazilian dental undergraduates. Braz Dent J. 2007;18(2):163-7.

31. Kroenke K, Spitzer RL, Williams JB. The PHQ-9: validity of a brief depression severity measure. J Gen Intern Med. 2001;16(9):606-13.

32. Spitzer RL, Kroenke K, Williams JB, Lowe B. A brief measure for assessing generalized anxiety disorder: the GAD-7. Arch Intern Med. 2006;166(10):1092-7.

33. Sawaya H, Atoui M, Hamadeh A, Zeinoun P, Nahas Z. Adaptation and initial validation of the patient health questionnaire - 9 (PHQ-9) and the generalized anxiety disorder - 7 questionnaire (GAD-7) in an Arabic speaking Lebanese psychiatric outpatient sample. Psychiatry Res. 2016;239: 245-52.

34. Barbour B, Saade N, Salameh PR. Psychological distress in Lebanese young adults: constructing the screening tool 'BDS-22'. Int J Cult Ment Health. 2012:5(2):94-108, https://doi.org/10.1080/17542863.2011.563043.

35. Newman AC, Omrani K, Higgins TS, Ting JY, Walgama ES, Wu AW. The prevalence of eustachian tube dysfunction symptoms in temporomandibular joint disorder patients. The Laryngoscope. 2020;130(4): E233-E236. https://doi.org/10.1002/lary.28162.

36. Goncalves DA, Dal Fabbro AL, Campos JA, Bigal ME, Speciali JG. Symptoms of temporomandibular disorders in the population: an epidemiological study. J Orofac Pain. 2010;24(3):270-8.

37. Casanova-Rosado JF, Medina-Solis CE, Vallejos-Sanchez AA, CasanovaRosado AJ, Hernandez-Prado B, Avila-Burgos L. Prevalence and associated factors for temporomandibular disorders in a group of Mexican adolescents and youth adults. Clin Oral Investig. 2006;10(1):42-9.

38. Shiau YY, Chang C. An epidemiological study of temporomandibular disorders in university students of Taiwan. Community Dent Oral Epidemiol. 1992;20(1):43-7.

39. Zwiri AM, Al-Omiri MK. Prevalence of temporomandibular joint disorder among north Saudi University students. Cranio. 2016;34(3):176-81.

40. Pedroni CR, De Oliveira AS, Guaratini MI. Prevalence study of signs and symptoms of temporomandibular disorders in university students. J Oral Rehabil. 2003;30(3):283-9.

41. Kitsoulis P, Marini A, lliou K, et al. Signs and symptoms of temporomandibular joint disorders related to the degree of mouth opening and hearing loss. BMC Ear Nose Throat Disord. 2011;11:5.

42. Oral K, Bal Kucuk B, Ebeoglu B, Dincer S. Etiology of temporomandibular disorder pain. Agri. 2009;21(3):89-94.

43. Yap AU, Dworkin SF, Chua EK, List T, Tan KB, Tan HH. Prevalence of temporomandibular disorder subtypes, psychologic distress, and psychosocial dysfunction in Asian patients. J Orofac Pain. 2003;17(1):21-8.

44. Pesqueira AA, Zuim PR, Monteiro DR, Ribeiro Pdo P, Garcia AR. Relationship between psychological factors and symptoms of TMD in university undergraduate students. Acta Odontologica Latinoamericana. 2010;23(3): 182-7.

45. Mottaghi A, Razavi SM, Pozveh EZ, Jahangirmoghaddam M. Assessment of the relationship between stress and temporomandibular joint disorder in female students before university entrance exam (Konkour exam). Dent Res J (Isfahan). 2011:8(Suppl 1):S76-9.

46. Al Hayek SO, Al-Thunayan MF, AlGhaihab AM, AlReshaid RM, Omair A. Assessing stress associated with temporomandibular joint disorder through Fonseca's anamnestic index among the Saudi physicians. Clin Exp Dental Res. 2018;5(1):52-8.

47. Habib SR, Al Rifaiy MQ, Awan KH, Alsaif A, Alshalan A, Altokais Y. Prevalence and severity of temporomandibular disorders among university students in Riyadh. Saudi Dent J. 2015;27(3):125-30.

48. Augusto VG, Perina KCB, Penha DSG, Dos Santos DCA, Oliveira VAS. Temporomandibular dysfunction, stress and common mental disorder in university students. Acta Ortop Bras. 2016;24(6):330-3.

49. Kawyannejad R, Mirzaei M, Valinejadi A, et al. General health of students of medical sciences and its relation to sleep quality, cell phone overuse, social networks and internet addiction. BioPsychoSocial medicine. 2019;13:12.

50. Ranjbaran M, Soleimani B, Mohammadi M, et al. Association between General Health and Mobile Phone Dependency among Medical University Students: A Cross-sectional Study in Iran. Int J Preventive Med. 2019;10:126.

51. Mohammadbeigi A, Absari R, Valizadeh F, et al. Sleep quality in medical students; the impact of over-use of Mobile cell-phone and social networks. Jes Health Sci. 2016;16(1):46-50.

52. Jun D, Zoe $M$, Johnston V, O'Leary S. Physical risk factors for developing non-specific neck pain in office workers: a systematic review and metaanalysis. Int Arch Occup Environ Health. 2017;90(5):373-410.

53. Tsang SMH, So BCL, Lau RWL, Dai J, Szeto GPY. Effects of combining ergonomic interventions and motor control exercises on muscle activity and kinematics in people with work-related neck-shoulder pain. Eur J Appl Physiol. 2018;118(4):751-65.

54. Vedolin GM, Lobato W, Conti PC, Lauris JR. The impact of stress and anxiety on the pressure pain threshold of myofascial pain patients. J Oral Rehabil. 2009;36(5):313-21.

55. Karam EG, Mneimneh ZN, Karam AN, et al. Prevalence and treatment of mental disorders in Lebanon: a national epidemiological survey. Lancet (London, England). 2006;367(9515):1000-6.

56. Abi Doumit C, Haddad C, Sacre H, et al. Knowledge, attitude and behaviors towards patients with mental illness: results from a national Lebanese study. PLoS One. 2019;14(9):e0222172.

57. Rayan A, Fawaz M. Cultural misconceptions and public stigma against mental illness among Lebanese university students. Perspectives Psychiatric Care. 2018;54(2):258-65.

58. Gatchel RJ, Stowell AW, Wildenstein L, Riggs R, Ellis E 3rd. Efficacy of an early intervention for patients with acute temporomandibular disorder- 
related pain: a one-year outcome study. J Am Dental Assoc (1939). 2006; 137(3):339-47.

59. Stepan L, Shaw CL, Oue S. Temporomandibular disorder in otolaryngology: systematic review. J Laryngol Otol. 2017;131(S1):S50-s56.

60. Ouanounou A, Goldberg M, Haas DA. Pharmacotherapy in Temporomandibular Disorders: A Review. Journal (Canadian Dental Association). 2017;83:h7.

61. Lavinsky D, Lavinsky J, Setogutti ET, Rehm DDS, Lavinsky L. The role of magnetic resonance imaging of the Temporomandibular joint to investigate tinnitus in adults with Temporomandibular joint disorder: a comparative study. Int Arch Otorhinolaryngology. 2020;24(1):e68-72.

\section{Publisher's Note}

Springer Nature remains neutral with regard to jurisdictional claims in published maps and institutional affiliations.

Ready to submit your research? Choose BMC and benefit from:

- fast, convenient online submission

- thorough peer review by experienced researchers in your field

- rapid publication on acceptance

- support for research data, including large and complex data types

- gold Open Access which fosters wider collaboration and increased citations

- maximum visibility for your research: over $100 \mathrm{M}$ website views per year

At BMC, research is always in progress.

Learn more biomedcentral.com/submissions 